\title{
Multiparameter Analysis for Efficiency Improvement of Single-Phase Capacitor Motor
}

\author{
Vasilija Sarac $(\mathbb{D})$ and Tatjana Atanasova-Pacemska $(\mathbb{D}$ \\ Faculty of Electrical Engineering, Goce Delcev University, P.O. Box 201, 2000 Stip, Macedonia \\ Correspondence should be addressed to Vasilija Sarac; saracvasilija@gmail.com
}

Received 2 January 2019; Revised 3 April 2019; Accepted 16 April 2019; Published 22 May 2019

Academic Editor: Yongheng Yang

Copyright (C) 2019 Vasilija Sarac and Tatjana Atanasova-Pacemska. This is an open access article distributed under the Creative Commons Attribution License, which permits unrestricted use, distribution, and reproduction in any medium, provided the original work is properly cited.

\begin{abstract}
Single-phase motors are known for their small power ratings and their usage in various household appliances. Although they are not large electricity consumers, their widespread application contributes to the overall electricity consumption. In addition, standard IEC 60034-30-1:214 defines the efficiency levels for single- and three-phase motors and stipulates the increased electrical efficiency for the electrical motors. Therefore, this paper sets the parametric analysis of permanently split capacitor motor with five different design parameters that have impact on the efficiency of the motor. As an output from the parametric analysis, two different optimized motor models are obtained with increased efficiency. The impact of each parameter on motor efficiency-as well as on the other operating characteristics, like starting torque, overloading capacity, rated current, starting current, total losses, and power factor-is analyzed and adequate conclusions are derived. The obtained motor models are verified with Finite Element Method (FEM) for magnetic flux density distribution.
\end{abstract}

\section{Introduction}

Capacitor motors belong to the single-phase motors that have a capacitor in the auxiliary winding usually aimed for motor starting. In the case of the permanently split capacitor motor, there is only one capacitor, placed in the auxiliary winding, which is permanently in operation, during starting as well as during motor running. In general, the single-phase motors have low power ratings but they are widespread in the household appliances and everywhere where single-phase supply is available. This makes the electricity consumption from the single-phase motors a considerable portion of the overall electricity consumption in the households and industry. In March 2014, the standard IEC 60034-30-1 has been published. It defines four efficiency classes for induction motors (single- and three-phase), IE1 standard efficiency, IE2 high efficiency, IE3 premium efficiency, and IE4 super premium efficiency (Figure 1). From $1^{\text {st }}$ January 2017 the legally specified minimum efficiency IE3 must be maintained for power ratings of electrical motors from $0.75 \mathrm{~kW}$ up to $375 \mathrm{~kW}$. Improving the motor efficiency has become an imperative for electrical motor producers. Nevertheless, the production costs should be maintained on competitive level through analyzing the various optimization aspects of the motors.

The optimization of the electrical motors with respect to the efficiency improvement based on the evaluation of the mechanical parameters and scaling laws at three-phase induction motors has been analyzed [2,3]. Optimization of single-phase capacitor motors has been investigated with triac-based voltage controller or in the drive configuration with Hall sensor $[4,5]$. Over the years, different optimization algorithms have been employed for the optimization of the single-phase motors such as particle swarm optimization, surrogate filed-circuit model, or genetic algorithms applied in single- or multiobjective optimization models [6-9]. Hybrid algorithm consisting of the particle swarm optimization and the genetic algorithms was applied in determining the optimal operating point of the two-phase motors regarding the increased efficiency and reduced torque ripple [10]. The last one presents the optimal motor operating point after optimization has been done and efficiency factor has been calculated by FEM. Artificial neural network controller has 


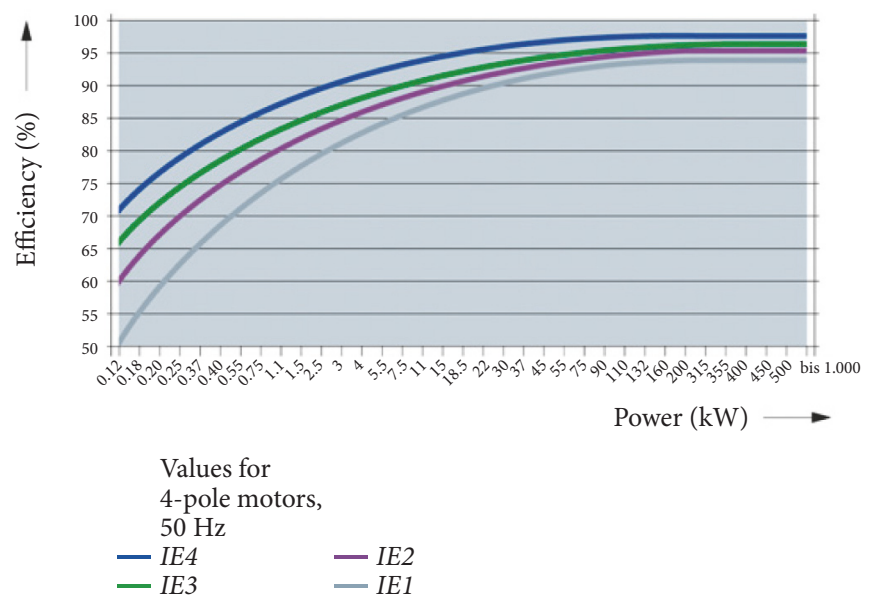

Figure 1: Coverage of IEC 60034-30-1 [1].

enhanced the efficiency and the dynamic responses of threephase induction motors particularly when the motors are operated at partial load [11]. Optimization of the induction motors advances further with the usage of fuzzy logic based controller acting as a supervisor in reducing flux levels during the transients and contributes to the efficiency improving of the dynamic operating modes [12]. Maximization of the efficiency at the induction motors is achieved by introducing mechanical improvement in stator and rotor core, i.e., slits in the middle of the stator and the rotor teeth $[13,14]$. This paper sets the comprehensive parametric analysis regarding efficiency improvement of permanently split capacitor motor and gives an overview of how the parameters are changed in optimized models in comparison to the starting model. The variations of all important operating parameters like starting and maximum torque, rated and starting current, current in main and auxiliary winding, losses in all motor parts as well as total losses, input and output power, rated torque, and power factor are also presented. Particularly the influence of each design parameter, which varies within certain limits, on the efficiency of the motor is presented. Consequently the paper gives major guidelines for motor designers about how the different design parameters (motor length, number of conductors of the main and the auxiliary winding, rotor diameter, and rotor slot opening) have influence on complete motor behavior during various operating modes: rated load, no-load, motor starting, and break-down operation. In addition, motor operation is evaluated by taking into consideration how maximization of the efficiency affects other operating conditions. Advantages and limitations of the proposed optimized models are also discussed. The starting motor model (BM) is a single-phase permanently split capacitor motor with rated data: voltage 220-240 V, frequency $50 \mathrm{~Hz}$, rated current $1.32 \mathrm{~A}$, rated power 124 $\mathrm{kW}$, product of the company MicronTech. Calculation of the operating characteristics of the single-phase capacitor motors is based on the method of symmetrical components and the double field revolving theory $[15,16]$. Often these analytical calculations require a lot of time due to the complex mathematical model of the motor that is becoming even more complex when the optimization is in question. In this paper Maxwell software for automated computing of motor performance is used allowing fast calculation of motor parameters and characteristics for various operating models and modes. The accuracy of the obtained results is highly dependent on the accuracy of the software model of the motor. Therefore, the starting motor model (BM) is verified by comparing its output results with available data from the motor's producer. Once the computer model is verified as sufficiently accurate, the parametric analysis is set by varying four different motor parameters in the first optimized motor model (M1): number of conductors in the main and the auxiliary stator winding, the motor axial length, and the outer diameter of the rotor. One more parameter is added in the second optimized motor model (M2) - the length of the rotor slot opening. The influence of the rotor slot distance from the rotor surface on the motor operating characteristics has been analyzed leading to the conclusion that motor performance is improved as the slot distance decreases [17]. The effect of the manufacturing process, which contributes to the larger fill factor of the rotor slots and its correlation with the motor efficiency, was investigated as well [18]. Closing the rotor slots raises additional questions about motor losses and core saturation in rotor slot bridges $[19,20]$. The closed rotor slots have significant impact on the no-load losses mainly due to the reduction of the losses at the slot upper part [21]. Therefore, the rotor slot opening is optimized in the second model leading to the motor construction with closed rotor slots. Both optimized models have increased efficiency in comparison with the starting model. Nowadays, FEM analysis is inevitable part of the motor design procedure as it verifies the feasibility of the proposed motor design in terms of magnetic core saturation at critical points of the motor construction [22-24]. The motor design procedure is completed by FEM analysis of the magnetic flux density distribution in the models cross-sections. 


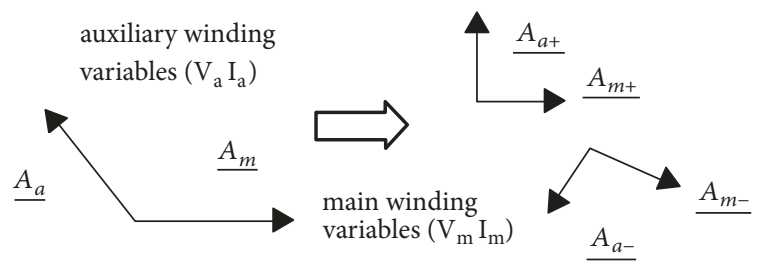

FIGURE 2: Symmetrical components of two-phase system.

\section{Mathematical Theory for Single-Phase Motor Modeling}

Despite its simple construction, the mathematical model of the single-phase motors, which describes the various motor operating modes, is quite complex due to the existence of the rotating elliptical electromagnetic field in the motor air gap. This air gap electromagnetic field is highly unsymmetrical; the application of the well-known theory and the mathematical models for the three-phase symmetrical induction motors is improper and inaccurate. Therefore, the unsymmetrical magnetomotive force $(\mathrm{mmf})$ currents and voltages corresponding to the two windings of single-phase induction machines may be decomposed in two symmetrical systems (Figure 2) which are the forward and backward components of the two-phase system [15].

Here following relations are valid:

$$
\begin{aligned}
& \underline{A_{a+}}=j \underline{A_{m+}} \\
& \underline{A_{a-}}=-j \underline{A_{m-}}
\end{aligned}
$$

where $A_{a}$ and $A_{m}$ are general variables associated with the auxiliary winding and main winding, respectively.

The superposition principle yields the following.

$$
\begin{aligned}
& \underline{A_{m}}=\underline{A_{m+}}+\underline{A_{m-}} \\
& \underline{A_{a}}=\underline{A_{a+}}+\underline{A_{a-}}
\end{aligned}
$$

The first step in the motor analysis is to determine all motor parameters: $\mathrm{R}_{\mathrm{sm}}$, main stator winding resistance; $\mathrm{X}_{\mathrm{sm}}$, main winding leakage reactance; $\mathrm{R}_{\mathrm{sa}}$, auxiliary stator winding resistance; $\mathrm{X}_{\mathrm{sa}}$, auxiliary stator winding leakage reactance; $\mathrm{X}_{\mathrm{mm}}$, magnetizing reactance; $\mathrm{R}_{\mathrm{rm}}$, rotor winding resistance; and $\mathrm{X}_{\mathrm{rm}}$, rotor winding leakage reactance [15]. Calculation of the motor parameters is based on the motor geometry obtained from the producer.

Based on the method of symmetrical components, impedance parameters $Z_{+}, Z_{-}$, and $Z_{a}^{m}$ are calculated, necessary for obtaining the symmetrical components of the stator currents and electromagnetic torque [15]:

$$
\underline{Z_{+}}=R_{s m}+j X_{s m}+j \frac{X_{m m}\left(X_{r m}+R_{r m} / s\right)}{R_{r m} / s+j\left(X_{m m}+X_{r m}\right)}
$$

where $s$ is the motor slip

$$
\begin{aligned}
\underline{Z_{-}}= & R_{s m}+j X_{s m}+j \frac{X_{m m}\left(X_{r m}+R_{r m} /(2-s)\right)}{R_{r m} /(2-s)+j\left(X_{m m}+X_{r m}\right)} \\
\underline{Z_{a}^{m}=} & \frac{1}{2}\left(\frac{R_{s a}}{a^{2}}-R_{s m}\right)+j\left(\frac{X_{s a}}{a^{2}}-X_{s m}\right)-j \\
& \cdot \frac{1}{2 \cdot a^{2} \cdot \omega \cdot C}
\end{aligned}
$$

where $\mathrm{C}$ is the capacitance in the auxiliary winding and $a$ is the ratio of the winding turns of the main and auxiliary stator winding. The symmetrical components of the currents of the main stator winding are calculated from

$$
\begin{aligned}
& \underline{I_{m+}}=\frac{V_{s}}{2} \cdot \frac{\left[(1-j / a) \underline{Z_{-}}+2 \underline{Z_{a}^{m}}\right]}{\underline{Z_{+}} \cdot \underline{Z_{-}}+\underline{Z_{a}^{m}}\left(\underline{Z_{+}}+\underline{Z_{-}}\right)} \\
& \underline{I_{m-}}=\frac{V_{s}}{2} \cdot \frac{\left[(1+j / a) \underline{Z_{+}}+2 \underline{Z_{a}^{m}}\right]}{\underline{Z_{+}} \cdot \underline{Z_{-}}+\underline{Z_{a}^{m}}\left(\underline{Z_{+}+} \underline{Z_{-}}\right)}
\end{aligned}
$$

where $V_{s}$ is the motor power supply voltage.

The supply line current is found from the following.

$$
I_{s}=\left|\underline{I_{m+}}+\underline{I_{m-}}+j \frac{I_{m+}-\underline{I_{m-}}}{a}\right|
$$

The currents in the main winding and the auxiliary stator winding are calculated, respectively.

$$
\begin{aligned}
& I_{m}=\left|\underline{I_{m+}}+\underline{I_{m-}}\right| \\
& I_{a}=\left|j \frac{I_{m+}-\underline{I_{m-}}}{a}\right|
\end{aligned}
$$

Components of the electromagnetic torque-direct and inverse are found:

$$
\begin{aligned}
& T_{e+}=\frac{2 p}{\omega_{1}} I_{m+}^{2}\left[\operatorname{Re}\left(\underline{Z_{+}}\right)-R_{s m}\right] \\
& T_{e-}=-\frac{2 p}{\omega_{1}} I_{m-}^{2}\left[\operatorname{Re}\left(\underline{Z_{-}}\right)-R_{s m}\right]
\end{aligned}
$$

where $\mathrm{p}$ is the pair of the motor poles.

Electromagnetic torque is as follows.

$$
T_{e}=T_{e+}+T_{e-}
$$

Motor input power is as follows.

$$
P_{1}=V_{s} I_{s} \cos \varphi
$$

The power factor becomes as follows.

$$
\cos \varphi=\frac{\operatorname{Re}\left(I_{s}\right)}{I_{s}}
$$

The motor output power $\mathrm{P}_{2}$ is obtained from the input power $\mathrm{P}_{1}$ after subtracting all motor losses $\mathrm{P}_{\Sigma \text { loss }}$, which can be 
divided into several groups: stator and rotor ohmic losses, capacitor losses, iron core losses, and mechanical losses.

Stator ohmic losses are calculated at temperature of $75^{\circ} \mathrm{C}$ as the sum of the ohmic losses in the main and the auxiliary winding.

$$
P_{c u 1}=R_{s m} I_{m}^{2}+R_{s a} I_{a}^{2}
$$

Capacitor losses can be found from

$$
P_{\text {cap }}=Z_{c} I_{a}^{2}
$$

where $Z_{c}$ is the capacitor impedance $Z_{c}=1 / j \omega C$.

According to [15] rotor ohmic losses at rated load can be approximately calculated as

$$
P_{c u 2}=I_{r m f}^{2} \frac{R_{r m}}{2}+I_{r m b}^{2} \frac{R_{r m}}{2}
$$

where $I_{r m b} \approx I_{m}$ and

$$
I_{r m f}=I_{m}\left|\frac{j X_{m m}}{R_{r m} / s+j\left(X_{m m}+X_{r m}\right)}\right| .
$$

Core losses are mainly eddy current and hysteresis losses that in analytical form can be expressed as follows.

$$
P_{F E}=k_{e} f^{2} B_{\max }^{2}+k_{h} f B_{\text {max }}^{\eta_{s t}}
$$

$k_{e}$ is the eddy current loss constant.

$B_{\max }$ is the maximum flux density.

$k_{h}$ is the hysteresis loss constant. 2).

$\eta_{s t}$ is the material dependant Steinmetz constant (1.6 to

Mechanical losses are mainly covering friction and windage losses. These losses can be determined by driving the motor at the rated speed with no-load or excitation. For the machines that operate at constant or nearly constant speed, these losses are constant. For an accurate calculation of motor losses, it is necessary to have an accurate calculation of motor parameters (resistances and reactances) as well as the currents in all motor windings. In addition, the magnetic flux density in the motor cross-section should be calculated, a parameter that is often more or less accurately predicted in motor analytical calculations. This emphasizes the need for an accurate computer-aided design of the motor capable of handling various design modifications, necessary for improving the motor efficiency factor $(\eta)$, which can be finally obtained from the ratio of the output power $\mathrm{P}_{2}$ and the input power $\mathrm{P}_{1}$.

$$
\eta=\frac{P_{2}}{P_{1}}
$$

\section{Computer-Aided Design of the Motor Models}

Accurate modeling of the motor in a software program for automated computing of parameters and operating characteristics of the single-phase capacitor motor is an important

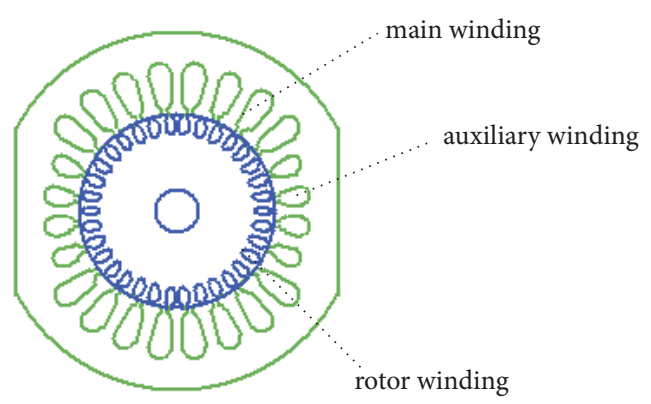

FIgURE 3: Motor model.

TABLE 1: Comparison between starting motor model and producer's data.

\begin{tabular}{lcc}
\hline & BM & Producer data \\
\hline Rated power $(\mathrm{W})$ & 124 & 124 \\
Rated torque $(\mathrm{Nm})$ & 0.416 & 0.411 \\
Rated speed (rpm) & 2846 & 2880 \\
Rated current $(\mathrm{A})$ & 1.35 & 1.32 \\
Maximum power $(\mathrm{W})$ & 210 & 210 \\
Maximum torque $(\mathrm{Nm})$ & 0.83 & 0.8 \\
\hline
\end{tabular}

TABLE 2: Variation ranges of motor design parameters.

\begin{tabular}{lcc}
\hline & Ranges of variation & Step \\
\hline Nr. of conductors in main slot $(/)$ & $110 \div 124$ & 1 \\
Nr. of conductors in auxiliary slot $(/)$ & $125 \div 135$ & 1 \\
Rotor diameter $(\mathrm{mm})$ & $65 \div 65.6$ & 0.1 \\
Motor core length $(\mathrm{mm})$ & $32 \div 37$ & 1 \\
Rotor slot opening $(\mathrm{mm})$ & $0 \div 1.5$ & 0.75 \\
\hline
\end{tabular}

step in the parametric analysis for efficiency improvement. Exact motor geometry is modeled with respect to the magnetic core dimensions and properties of the core material, i.e., magnetization curve $B=f(H)$, with $B$ being the magnetic flux density and $\mathrm{H}$ being the magnetic field strength (Figures 3 and 4).

Properties of core laminations are defined in accordance with lamination type DL 80, RK502.4. Electric properties of the materials are modeled as well. Stator winding, consisting of main and auxiliary winding made of copper, is placed in the main and the auxiliary slots. Rotor winding is of squirrel cage type, made of aluminum. Motor is aimed for constant power operation and it is modeled in the software program Maxwell using available data from the motor's producer. The accuracy of the developed starting model (BM) is verified by comparing the output results from the model and available data from the producer. Table 1 presents this comparison.

Once the starting model has been verified as sufficiently accurate, the parametric analysis is set by varying several motor parameters within the predefined boundaries. The variation ranges of the parameters are presented in Table 2.

As a first step in the parametric analysis, four varied parameters were defined: the number of the conductors in the 


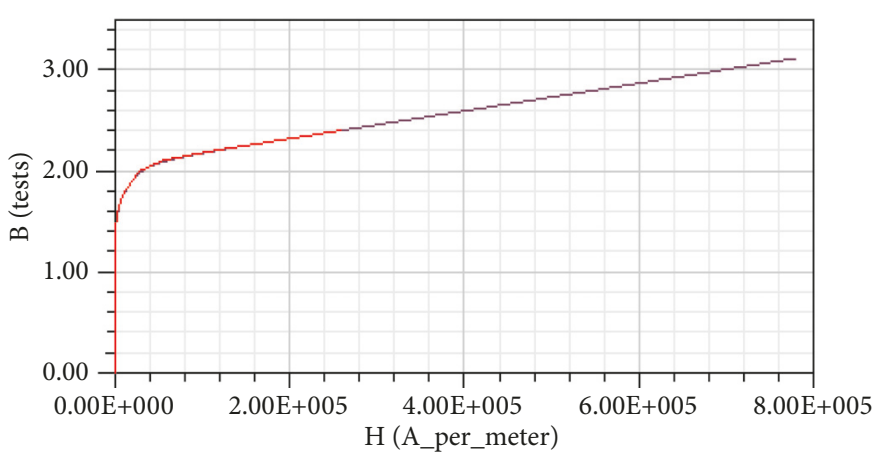

FIGURE 4: Magnetization characteristic of core material.

main and the auxiliary stator slot, length of magnetic core, and rotor diameter, i.e., the length of the air gap between the stator and the rotor. The parametric analysis resulted in 8085 different combinations that were solved. Out of these solutions, the best result or the best motor model in terms of the maximum efficiency at rated load was selected (model M1). The second parametric analysis was defined by adding one more varied parameter, i.e., the length of the rotor slot opening, and by taking into consideration the previous four varied parameters. This second parametric analysis resulted in 17325 different combinations. Their solutions gave the second motor model (M2) with better efficiency than BM and M1. In the next step, motor models are verified by FEM for magnetic flux density distribution. The flux density $\mathbf{B}$ is calculated from the magnetic vector potential A. In order for Maxwell's equations to be solved, the complete machine cross-section is divided into numerous elements forming the mesh of finite elements (Figure 5). The electromagnetic field problems are solved by solving Maxwell's equations in a finite region of space with appropriate boundary conditions and user-specific initial conditions in order to obtain solution with guaranteed uniqueness.

$$
\begin{aligned}
& \nabla x \mathbf{H}=J+\frac{\partial \mathbf{D}}{\partial t} \\
& \nabla x \mathbf{E}=-\frac{\partial \mathbf{B}}{\partial t} \\
& \nabla \cdot \mathbf{D}=\rho \\
& \nabla \cdot \mathbf{B}=0
\end{aligned}
$$

where $\mathbf{E}$ is the electric field, $\mathbf{D}$ is the electric displacement equal to $\varepsilon \mathbf{E}, \varepsilon$ is the permittivity, $\mathbf{B}$ is the magnetic flux density, and $\mathbf{H}$ is the magnetic field, equal to the product of material magnetic permeability and magnetic flux density, $\mu \mathbf{B}$. $J$ is the current density, $\sigma \mathbf{E}$, where $\sigma$ is the conductivity. $\rho$ is the charge density.

The FEM discretization of the domain of the analyzed object produces a set of matrix differential equations. They are solved with the time decomposition method (TDM). The domain is decomposed along the time axis and all time steps are solved simultaneously instead of solving them time step by time step. The nonlinear matrix equations are linearized

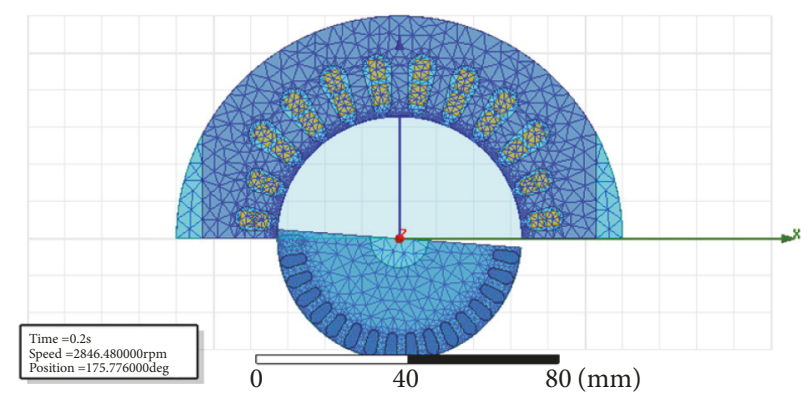

FIGURE 5: Finite elements mesh in motor cross-section.

for each of the nonlinear iterations. As an output from the FEM model, motor torque is calculated for all motor models. The comparison of the obtained torque from all FEM models with the torque from the parametric analysis verifies the accuracy of the FEM model.

\section{Results and Discussions}

4.1. Parametric Analysis. The output results from the parametric analysis give an overview of all important motor parameters and data. Motor parameters of all three models (BM, M1, and M2) are presented in Table 3 together with the output results from the parameters variations that resulted in the best motor models in terms of efficiency. All parametric analyses are run for constant power operation; i.e., all motors should have the same output power. The type of the winding is two-layer sinusoidal winding.

For the best motor model in terms of efficiency besides motor parameters, motor operation in three typical operating modes, i.e., the rated load, the locked rotor, and the noload, is analyzed. Table 4 provides the motor operating characteristics for the rated load. Here, an overview of all motor losses is presented as well. Mechanical losses (frictional and windage losses) were calculated as $9 \%$ of the total losses as often they are within range of 8-12 percent of the total losses. The no-load operating characteristics are presented in Table 5 together with the motor locked rotor (starting) characteristics. Detailed presentation of motor operation for different speeds is presented in Figures 6, 7, 8, and 9. Figure 6 presents the input (line) current for different speeds. 
TABLE 3: Motor parameters.

\begin{tabular}{|c|c|c|c|}
\hline Motor parameter & $\mathrm{BM}$ & M1 & M2 \\
\hline Nr. of conductors per layer in main winding $-\mathrm{W}_{\mathrm{m}}(/)$ & 117 & 124 & 124 \\
\hline Nr. of conductors per layer in auxiliary winding $-\mathrm{W}_{\mathrm{a}}(/)$ & 130 & 125 & 125 \\
\hline Core length- $\mathrm{L}(\mathrm{mm})$ & 35 & 37 & 37 \\
\hline Rotor diameter- $\mathrm{R}_{\mathrm{o}}(\mathrm{mm})$ & 65.4 & 65.6 & 65.6 \\
\hline Rotor slot opening -RSO (mm) & 1.5 & 1.5 & 0 \\
\hline Main winding resistance at $20^{\circ} \mathrm{C}-\mathrm{R}_{\mathrm{sm}}(\Omega)$ & 25.376 & 27.16 & 27.16 \\
\hline Auxiliary winding resistance at $20^{\circ} \mathrm{C}-\mathrm{R}_{\mathrm{sa}}(\Omega)$ & 69.14 & 67.05 & 67.056 \\
\hline Main winding reactance- $\mathrm{X}_{\mathrm{sm}}(\Omega)$ & 16.24 & 19.18 & 19.38 \\
\hline Auxiliary winding reactance- $\mathrm{X}_{\mathrm{sa}}(\Omega)$ & 24.66 & 23.8 & 24 \\
\hline Rotor resistance- $\mathrm{R}_{\mathrm{rm}}(\Omega)$ & 22.31 & 25.66 & 25.98 \\
\hline Rotor reactance- $\mathrm{X}_{\mathrm{rm}}(\Omega)$ & 3.53 & 4.81 & 21.525 \\
\hline Magnetizing reactance- $\mathrm{X}_{\mathrm{mm}}(\Omega)$ & 387.18 & 702.3 & 784.57 \\
\hline Capacitance-C $(\mu \mathrm{F})$ & 6 & 6 & 6 \\
\hline
\end{tabular}

TABLE 4: Rated load operation.

\begin{tabular}{|c|c|c|c|}
\hline Motor characteristic & $\mathrm{BM}$ & M1 & M2 \\
\hline Rated speed $n_{n}(r p m)$ & 2846.48 & 2831.72 & 2831.72 \\
\hline Line current $I_{s}(A)$ & 1.35 & 1.1788 & 1.159 \\
\hline Main winding current density $\left(\mathrm{A} / \mathrm{mm}^{2}\right)$ & 4.422 & 3.6562 & 3.608 \\
\hline Auxiliary winding current density $\left(\mathrm{A} / \mathrm{mm}^{2}\right)$ & 3.6 & 3.38 & 3.284 \\
\hline Main winding current $\mathrm{I}_{\mathrm{m}}(\mathrm{A})$ & 1.0166 & 0.84 & 0.829 \\
\hline Auxiliary winding current $\mathrm{I}_{\mathrm{a}}(\mathrm{A})$ & 0.3693 & 0.346 & 0.336 \\
\hline Capacitor losses $\mathrm{P}_{\text {cap }}(\mathrm{W})$ & 72.378 & 63.54 & 59.98 \\
\hline Iron core losses $\mathrm{P}_{\mathrm{FE}}(\mathrm{W})$ & 4.487 & 3.93 & 3.13 \\
\hline Stator ohmic losses $\mathrm{P}_{\mathrm{cul}}(\Omega)$ & 43.345 & 33.083 & 31.9 \\
\hline Rotor ohmic losses $\mathrm{P}_{\mathrm{cu} 2}(\Omega)$ & 15.91 & 16.603 & 16.34 \\
\hline Mechanical losses (W) & 13.424 & 13.28 & 13.28 \\
\hline Total losses $\mathrm{P}_{\Sigma \text { Ioss }}(\mathrm{W})$ & 149.545 & 130.454 & 124.67 \\
\hline Input power $\mathrm{P}_{1}(\mathrm{~W})$ & 273.552 & 254.352 & 248.7 \\
\hline Output power $\mathrm{P}_{2}(\mathrm{~W})$ & 124 & 123.89 & 124.04 \\
\hline Efficiency factor (eta) $\eta(\%)$ & 45.332 & 48.7 & 49.87 \\
\hline Output torque $\mathrm{T}(\mathrm{Nm})$ & 0.416 & 0.4178 & 0.418 \\
\hline Maximum torque $\mathrm{T}_{\max }(\mathrm{Nm})$ & 0.83 & 0.775 & 0.754 \\
\hline Power factor $\cos \varphi(/)$ & 0.919 & 0.98 & 0.975 \\
\hline Rated slip $s_{n}(/)$ & 0.051 & 0.056 & 0.056 \\
\hline
\end{tabular}

From Table 4 it can be observed that motor line current is decreased in both optimized models. The decrease of the line current is mainly the result of the increased resistance of the main winding due to the increase of the number of conductors in the main winding. The decreased line current leads to the decreased input power $\mathrm{P}_{1}$ or electricity consumption (15). The decreased input power affects the motor efficiency factor. The decrease of the current resulted in decreased ohmic losses in the stator windings (17). The parametric analysis is done with the motor output power as a constraint; i.e., output power should be kept constant which implies almost unchanged output torque as the relation between the output power and the torque is directly proportional. Some variations of the rated speed in different motor models that affect the rated output torque are possible, but in these particular models, they are not so emphasized. By taking into consideration that efficiency factor is defined with the ratio of the output and the input power, keeping the output power constant is forcing the decrease of the input power and the motor losses in order to achieve better efficiency factor than in the starting model. The smaller the motor losses, the better the obtained efficiency factor. As the electricity consumption of the motor is decreased, this leads to an energy efficient motor. This is the case with M1 and M2, with both models having smaller total losses than BM.

From Table 4 and the presented diagrams in Figure 7, it can be concluded that in the optimized models the power factor is increased. The increase of the power factor is a 
TABLE 5: No-load and locked rotor operation.

\begin{tabular}{|c|c|c|c|}
\hline Motor characteristic & $\mathrm{BM}$ & M1 & M2 \\
\hline Main winding reactance $\mathrm{X}_{\mathrm{sm}}(\Omega)$ & 15.96 & 18.7 & 18.7 \\
\hline Auxiliary winding reactance $\mathrm{X}_{\mathrm{sa}}(\Omega)$ & 24.31 & 23.37 & 23.4 \\
\hline Rotor reactance $\mathrm{X}_{\mathrm{rm}}(\Omega)$ & 3.24 & 4.3 & 47.59 \\
\hline Magnetizing reactance $\mathrm{X}_{\mathrm{mm}}(\Omega)$ & 283.34 & 524.48 & 552.5 \\
\hline No-load line current $\mathrm{I}_{0}(\mathrm{~A})$ & 1.15 & 0.6799 & 0.653 \\
\hline No-load current main winding $\mathrm{I}_{\mathrm{m} 0}(\mathrm{~A})$ & 0.953 & 0.423 & 0.392 \\
\hline No -load current auxiliary winding $\mathrm{I}_{\mathrm{a} 0}(\mathrm{~A})$ & 0.413 & 0.39 & 0.386 \\
\hline No-load iron core losses $\mathrm{P}_{\mathrm{FE} 0}(\mathrm{~W})$ & 5.27 & 4.787 & 3.82 \\
\hline No-load input power $\mathrm{P}_{0}(\mathrm{~W})$ & 156.244 & 118.96 & 114.97 \\
\hline No-load power factor $\cos \varphi_{0}(\mathrm{~W})$ & 0.614 & 0.795 & 0.8 \\
\hline No-load speed $n_{0}(\mathrm{rpm})$ & 2985.91 & 2986.7 & 2986.7 \\
\hline Starting torque $\mathrm{T}_{\mathrm{p}}(\mathrm{Nm})$ & 0.116 & 0.11 & 0.111 \\
\hline Starting line current $I_{P}(A)$ & 4.077 & 3.658 & 3.53 \\
\hline Starting current main winding $\mathrm{I}_{\mathrm{mp}}(\mathrm{A})$ & 3.9325 & 3.519 & 3.4 \\
\hline Starting current auxiliary winding $\mathrm{I}_{\mathrm{ap}}(\mathrm{A})$ & 0.2704 & 0.2712 & 0.272 \\
\hline
\end{tabular}

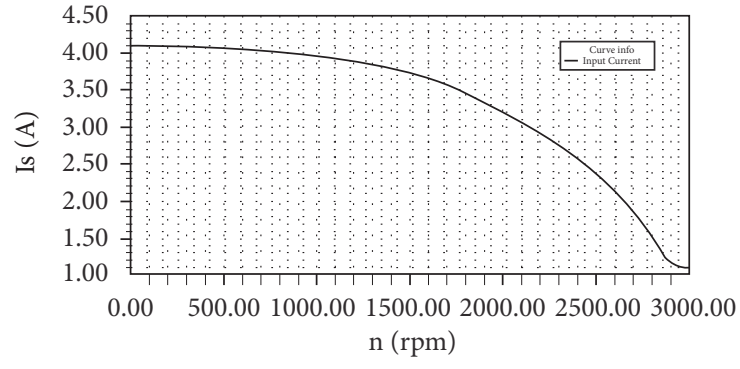

(a) $\mathrm{BM}$

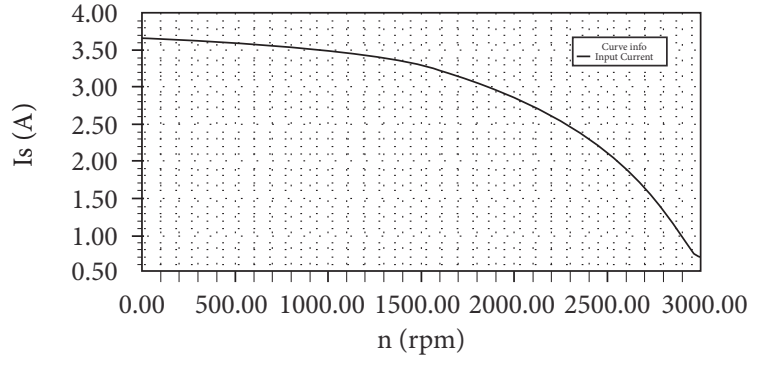

(b) M1

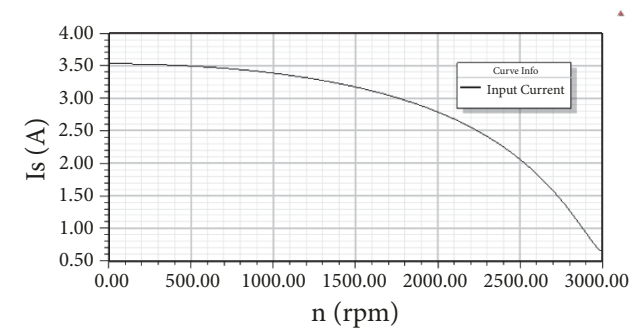

(c) M2

FIGURE 6: Line supply current for various speeds.

result of the decreased air gap due to the increased rotor diameter. In general, based on the designing experience, recommendation for the air gap length is [15]

$$
g=\left(0.1+0.02 \cdot \sqrt[3]{P_{n}}\right) \cdot 10^{-3}[\mathrm{~m}]
$$

where $g$ is the air gap length and $P_{n}$ is the rated output power. Therefore, by taking into consideration (27) and the motor rated power, it is estimated that the air gap can be further reduced. In general, the air gap between the stator and the rotor is a critical part of the motor construction. The length of the air gap affects the performance parameters like magnetizing current, overload capacity, cooling, and noise. A too small air gap would produce large space air gap harmonics and additional losses, while a too large one would reduce the power factor and the efficiency [15]. The larger air gap has some advantages and disadvantages. Among the advantages are increased overload capacity, increased cooling, reduced unbalanced magnetic pull, and reduced noise. The disadvantages are the increased magnetizing current and the reduced power factor. As expected, the optimized models are behaving in accordance with the aforementioned general rules. The overload capacity of optimized models is decreased (decreased maximum torque, Table 4 ) and the noload current is decreased as well, due to the smaller air gap. The power factor and the efficiency are also increased. The influence of the current density of the stator windings on the overall motor design is analyzed as well. As a general 


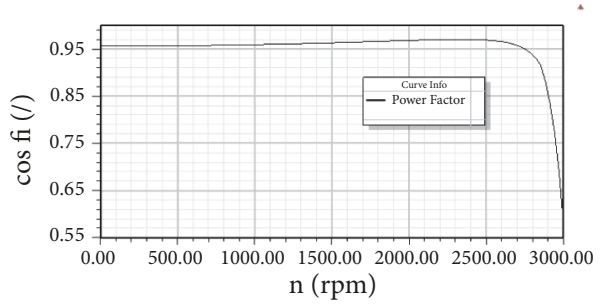

(a) $\mathrm{BM}$

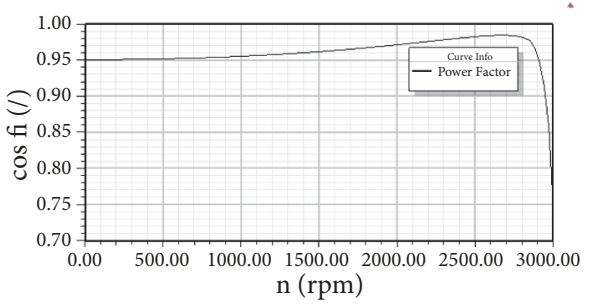

(b) M1

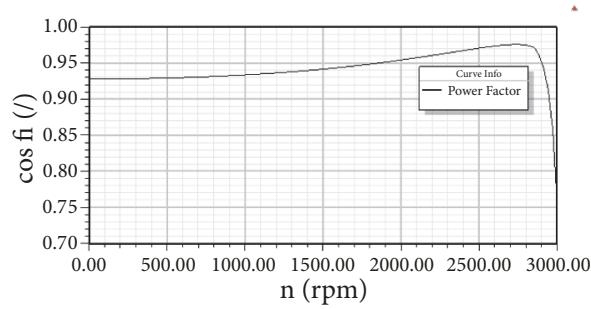

(c) M2

FIgURE 7: Power factor for various speeds.

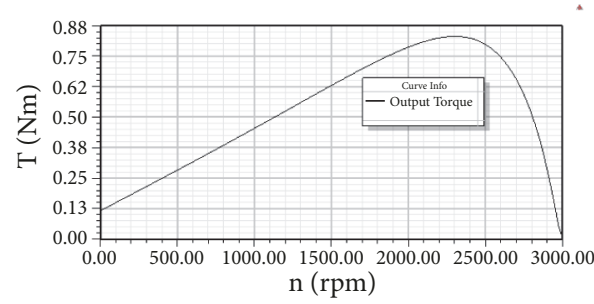

(a) BM

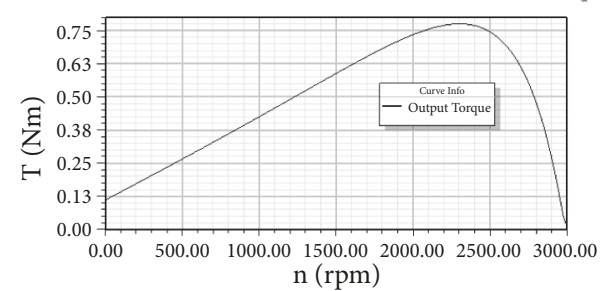

(b) M1

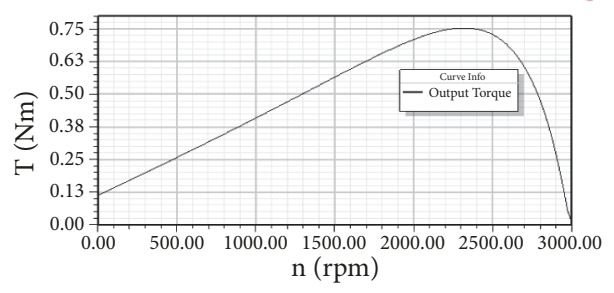

(c) M2

FIGURE 8: Output torque for various speeds.

recommendation, the current density of the stator windings should be within 3-5 A/mm ${ }^{2}$. The higher values of current densities have some advantages like reduction in the copper cross-section, the weight, and consequently the cost of the machine. The disadvantages are increase of the resistance, copper losses, and temperature rise followed by the reduction of the efficiency. As the models M1 and M2 have the decreased current density compared with the BM, they have lower resistance, decreased copper losses, and increased efficiency (Table 5). Figure 8 presents the output torque for all three motor models. As expected, due to the almost unchanged output power $\mathrm{P}_{2}$ and slight variations of rated speed $\mathrm{n}_{\mathrm{n}}$, in all motor models, the output torque remains almost unchanged in all models for the rated load mode. The output torque and the output power are related to the following well-known equation.

$$
T=9.55 \cdot\left(\frac{P_{2}}{n_{n}}\right)
$$

The efficiency factor for various speeds and for all motor models is presented Figure 9. The third model has the highest efficiency due to the last varied parameter, the length of the rotor slot opening. Generally, semiclosed slots or closed slots with very small or narrow openings are used in the construction of the rotor. The rotor with closed slots affects the motor performance in the following way: the rotor surface is smooth at the air gap, motor draws lower magnetizing current, and the noise and the starting current are reduced. 


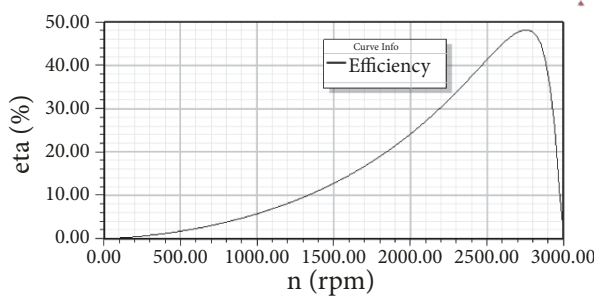

(a) $\mathrm{BM}$

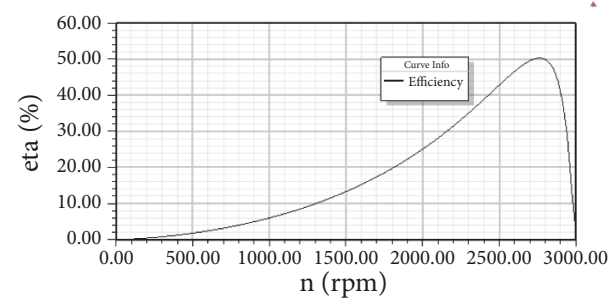

(b) M1

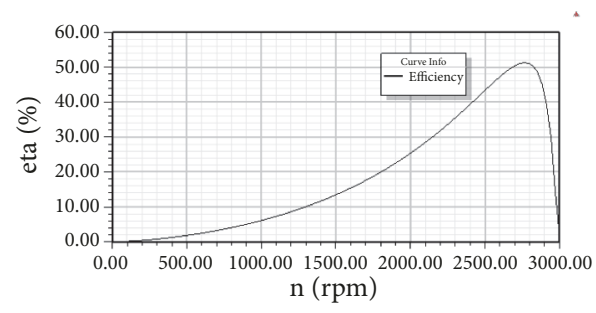

(c) $\mathrm{M} 2$

Figure 9: Efficiency for various speeds.

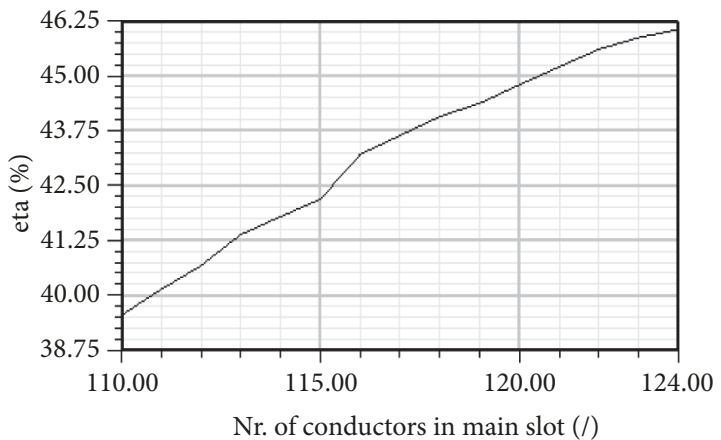

(a) $\mathrm{W}_{\mathrm{m}}$ is a variable parameter

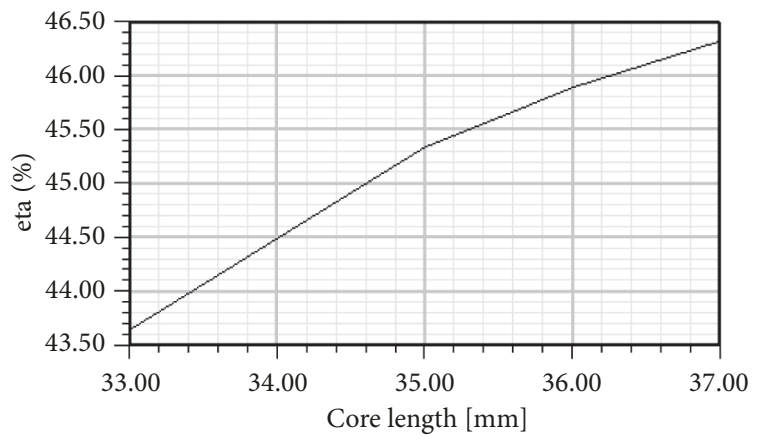

(c) $\mathrm{L}$ is a variable parameter

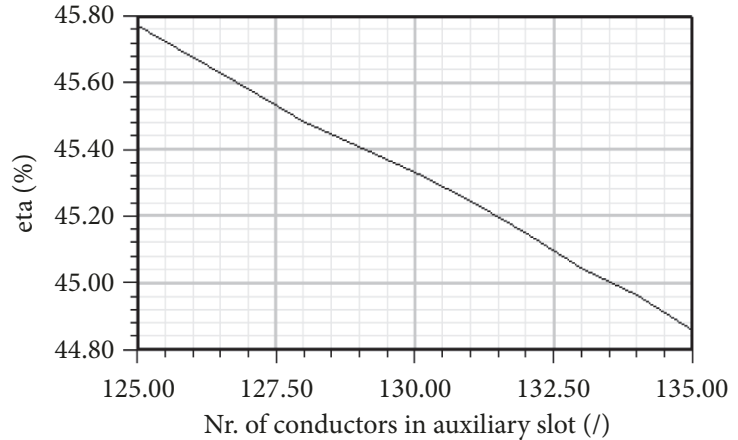

(b) $\mathrm{W}_{\mathrm{a}}$ is a variable parameter

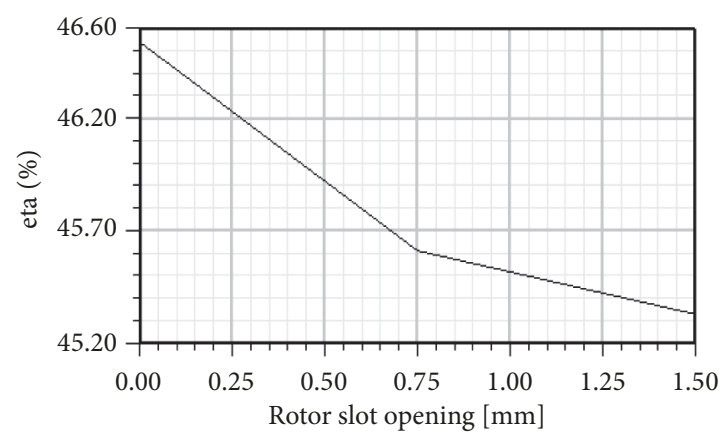

(d) RSO is a variable parameter

FIGURE 10: Influence of different parameters on motor efficiency.

In our models (M1 and M2), the no-load current is decreased (since the magnetizing current equals no-load current at noload operation), the leakage inductance is increased, and the starting current is reduced (Table 5). The disadvantage of the closed rotor slots is the reduction of the motor overload capacity. This is also the case with M1 and M2 models, which have the decreased maximum torque compared with $\mathrm{BM}$ model (Table 4).
The influence of the variation of different design parameters on overall motor efficiency is presented in Figure 10. Diagrams are obtained by keeping the starting motor configuration and by varying only one parameter (i.e., Figure 10(a), $\mathrm{W}_{\mathrm{m}}$ is variable, $\mathrm{W}_{\mathrm{a}}=130, \mathrm{~L}=35 \mathrm{~mm}, \mathrm{R}_{\mathrm{o}}=65.4 \mathrm{~mm}, \mathrm{RSO}=1.5$ $\mathrm{mm}$ ). In Figure $10(\mathrm{~b}) \mathrm{W}_{\mathrm{a}}$ is variable while all the other parameters remain the same as in the starting model, BM. On the same principle, the other results in Figure 10 are obtained. 


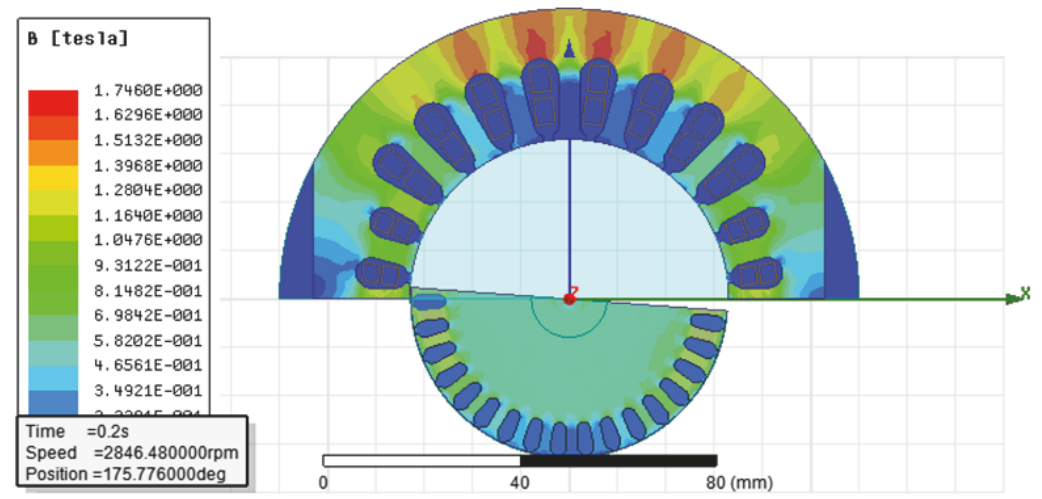

(a) $\mathrm{BM}$

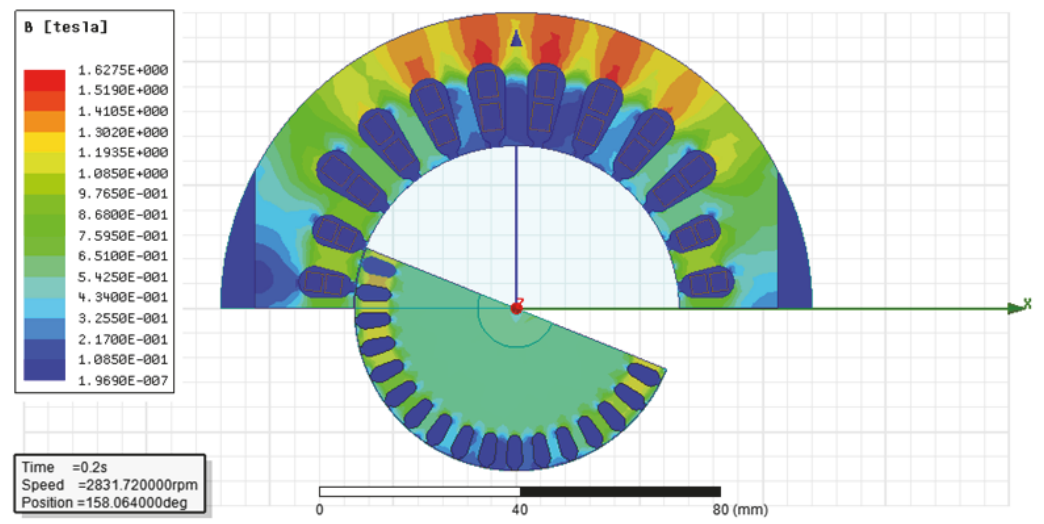

(b) M1

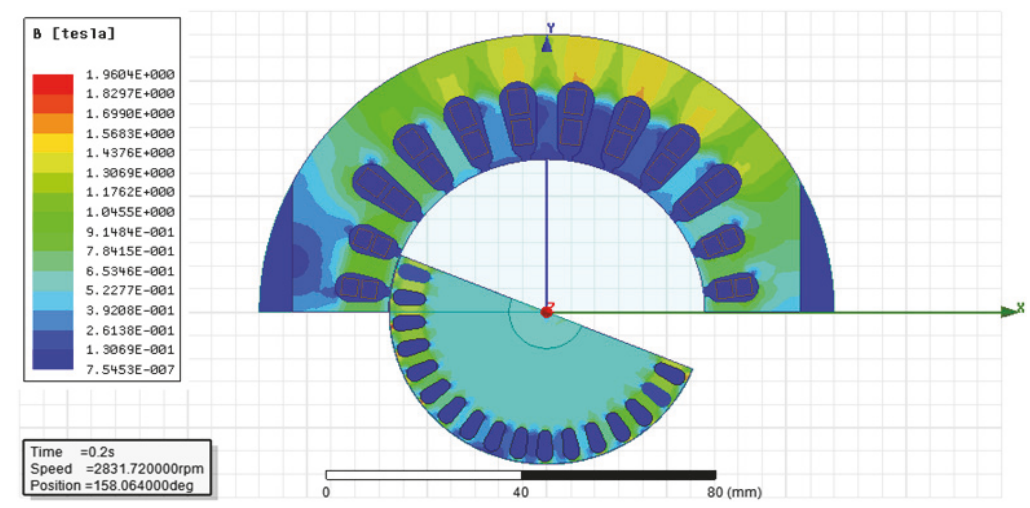

(c) $\mathrm{M} 2$

Figure 11: Flux density distribution.

The efficiency increases with the increase of the conductors in the main winding, the decrease of the main winding current, and the decrease of the copper losses.

Motor output power $\left(\mathrm{P}_{2}\right)$ is proportional to product $\mathrm{D}^{2} \mathrm{~L}$ where $\mathrm{D}$ is the stator bore diameter and $\mathrm{L}$ is the core length [15]. Consequently, the increase of motor length gives the increase of the motor output power and the increase of the motor efficiency $(\eta)$ since output and input power of the motor are related to (22). This type of the motor has increased current magnitude with backward time shift and the increased torque pulsations as the motor approaches the rated speed. To reduce this, the impedance in the auxiliary winding should be reduced and consequently the losses are minimized; i.e., number of conductors in auxiliary winding is decreased (Figure 10(b)).

4.2. FEM Analysis. Parametric analysis serves as a starting point for deriving motor FEM model for verification of proposed models (M1 and M2) in terms of magnetic flux density distribution. Figure 11 presents the distribution of the magnetic flux density for all motor models. 


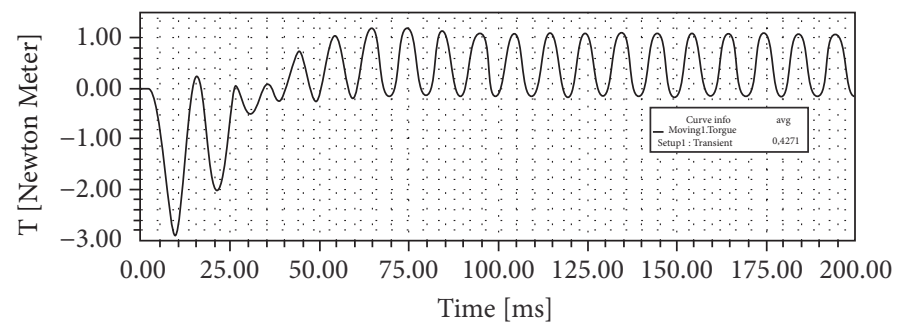

(a) $\mathrm{BM}$

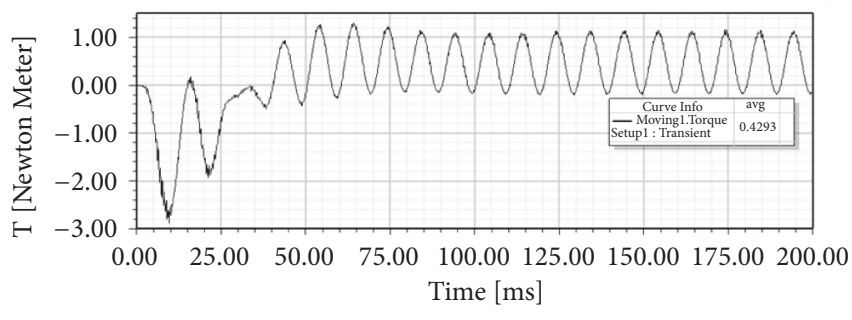

(b) M1

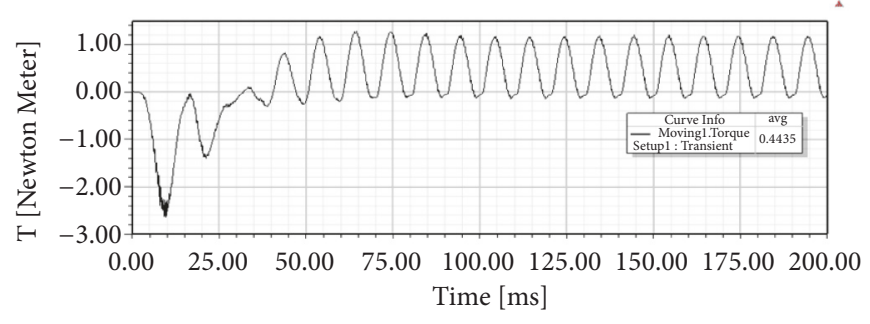

(c) M2

Figure 12: Output torque in FEM models.

TABLE 6: Comparison of output torque-FEM and parametric analysis at rated load.

\begin{tabular}{lcc}
\hline Output torque $(\mathrm{Nm})$ & Parametric analysis & FEM analysis \\
\hline BM & 0.4135 & 0.4271 \\
M1 & 0.4178 & 0.4293 \\
M2 & 0.418 & 0.4435 \\
\hline
\end{tabular}

There are some general recommendations for the flux density in the specific parts of the machine. For the stator and the rotor teeth, it should be less than $1.8 \mathrm{~T}$, and for the core (yoke) between 1.3 and $1.5 \mathrm{~T}$ [15]. Following these general recommendations, the flux density distribution is within recommended ranges for BM and $\mathrm{M} 1$. As for the second optimized model M2, bigger values of the flux density can be observed in the rotor teeth due to the motor construction with closed rotor slots. Yet, this value of the flux density is still below the point of the core saturation with respect to the built-in core material as the saturation point is approximately at 2T (Figure 3 ). FEM models of the motors are verified in terms of their accuracy by calculating the output torque for one fixed speed. It should be noted that presented diagrams of the torque in Figure 12 do not represent the motor transient characteristics usually plotted during motor acceleration from zero up to the rated speed. The presented diagrams are calculating motor torque at one constant speed, i.e., rated speed, for each of the motor models, within the whole interval. Table 6 presents the comparison between the torque values from the parametric analysis and from the FEM models at rated load operating mode. As the torque in the FEM models has pronounced oscillations, it is calculated as an average value within the time interval from 175 to $200 \mathrm{~ms}$. The presented results in Table 6 and their similarity verify that the FEM models are sufficiently accurate. Therefore, the presented results of the flux density distribution are considered reliable and contribute to the overall estimation of the motor design and the performance.

\section{Conclusion}

Single-phase capacitor motors are large electricity consumers if their relative high number in various electrical household appliances is taken into consideration. Therefore, the slight improvement of their efficiency contributes to the overall energy efficiency. The paper presents the impact of several motor parameters such as number of conductors in main and auxiliary winding, machine length, air gap length, and opening of the rotor slots on the efficiency of the permanently split capacitor motor. Parametric analysis was run in Maxwell software which resulted in two improved motor models, M1 and M2, with increased efficiency of $7.4 \%$ and $10 \%$, respectively, compared with the starting motor model. The difference between models M1 and M2 is the width of rotor slot opening, with the latter having completely closed rotor slots. The models obtained from the parametric analysis were verified with FEM in terms of the magnetic flux density distribution. The results from the FEM analysis proved that model M1 is well designed with respect to the magnetic flux density distribution as the flux density in machine crosssection is within the recommended intervals for the various parts of the machine. Model M2 has the highest value of flux density in rotor teeth although this value is still below the point of core saturation for the built-in magnetic material. The accuracy of the derived FEM models is verified with the similarity of the obtained results of the output torque from FEM and the parametric analysis. By using the latest advancements in the designing programs for the electrical machines, different motor models can be derived in relatively short computing time, resulting in the best possible motor design in terms of predefined objective function. Alterations 
in the motor design are easily inputted; the results are quickly obtained giving motor's designers freedom to explore the different motor variants and to find the best design for a certain application. This paper provides a comprehensible overview of the design parameters of the single-phase permanent split capacitor motor and their impact on the motor efficiency. In order to have comparable results, all motor models are derived with the same capacitor as it affects the motor performance. Authors' further research will be focused on finding the optimal capacitor value for providing the best starting and operating conditions of the motor.

\section{Data Availability}

The data used to support the findings of this study are included within the article.

\section{Conflicts of Interest}

The authors declare that there are no conflicts of interest regarding the publication of this paper.

\section{Acknowledgments}

The work was supported by the project "Contributions in Mathematical Theory, Mathematical Modeling and Their Application", financed by "Goce Delcev" University.

\section{References}

[1] “Siemens: Efficiency classes for IEC motor," https://www.industry.siemens.com/drives/global/en/motor/low-voltage-motor/efficiency-standards/pages/line-motors.aspx.

[2] J. Li and J. Shen, "Influence of mechanical parameters on power efficiency of induction motors," in Proceedings of the 2014 17th International Conference on Electrical Machines and Systems (ICEMS), pp. 2555-2560, Hangzhou, China, October 2014.

[3] D. Žarko, S. Frljić, and S. Stipetić, "Design of premium efficiency (IE3) induction motors using evolutionary optimization and scaling laws," Przegląd Elektrotechniczny, vol. 92, no. 12, pp. 181184, 2016.

[4] C. Mademlis, I. Kioskeridis, and T. Theodoulidis, "Optimization of single-phase induction motors - Part I: Maximum energy efficiency control," IEEE Transactions on Energy Conversion, vol. 20, no. 1, pp. 187-195, 2005.

[5] X. Wang, D. Meng, and Y. Xu, "Analysis of single-phase induction motors efficiency optimization control with hall sensor," Advances Science and Technology Letters, vol. 53, pp. 357-360, 2014.

[6] V. Rashtchi and A. Ghasemian, "Efficiency optimization of induction motor drive using modified particle swam optimization," in Proceedings of the International Conference on Electrical, Electronics and Instrumentation Engineering, pp. 1418, Johannesburg, South Africa, 2013.

[7] A. M. Sharf and A. A. El-Gammal, "A new technique for maximum efficiency and minimum electrical energy consumption of single phase induction motors based on particle swarm optimization (PSO)," in Proceedings of the 16th National Power Systems Conference, pp. 12-17, Hyderabad, India, 2010.
[8] K. Makowski and M. J. Wilk, "Optimization of a single-phase capacitor induction motor by applying a surrogate field-circuit model," COMPEL - The International Journal for Computation And Mathematics in Electrical And Electronic Engineering, vol. 33, no. 6, pp. 1891-1903, 2014.

[9] S. Szenasi and I. Felde, "Configuring genetic algorithm to solve the inverse heat conduction problem," Acta Polytechnica Hungarica, vol. 14, no. 6, pp. 133-152, 2017.

[10] N. Horiyat, S. M. Shariatmadar, and V. Amir, "Optimization of an experimental unsymmetrical-unbalanced two-phase induction motor using the HGAPSO hybrid technique and the finite element method for increasing efficiency and reducing torque ripple," Turkish Journal of Electrical Engineering \& Computer Sciences, vol. 24, pp. 4154-4173, 2016.

[11] P. K. Choudhary and S. P. Dubey, "Efficiency optimization of induction motor drive in steady-state using artificial neural network," in Proceedings of the 2016 International Conference on Computation of Power, Energy Information and Commuincation (ICCPEIC), pp. 295-302, Melmaruvathur, Chennai, India, April 2016.

[12] L. Ramesh, S. P. Chowdhury, S. Chowdhury, and Y. H Song, "Efficiency optimization of induction motor using a fuzzy logic based optimum flux search controller," in Proceedings of the International Conference on Power Electronics, Drives and Energy Systems, pp. 1-6, 2006.

[13] A. G. Yetgin and M. Turan, "Efficiency optimization of slitted-core induction motor," Journal of Electrical Engineering, vol. 65, no. 1, pp. 60-64, 2014.

[14] A. G. Yetgin and M. Turan, "Efficiency improvement in induction motor by slitted tooth design," Technical Gazette, vol. 24, no. 5, pp. 1291-1296, 2017.

[15] I. Boldea and S. A. Nasar, The Induction Machines Design Handbook, CRC Press, 2nd edition, 2010.

[16] C. E. Feraga and A. Bouldjedi, "Performance of a photovoltaic pumping system driven by a single phase induction motor connected to a photovoltaic generator," Automatika, vol. 57, no. 1, pp. 163-172, 2016.

[17] M. S. Kurt and A. Fenercioğlu, "Rotor slot distance effects on output parameters in single phase induction motors," Hittite Journal of Science \& Engineering, vol. 5, no. 1, pp. 31-35, 2018.

[18] H. Ahn, K. Kim, J. Choi, E. Kim, and Y. Lim, "Rotor design for an efficient single-phase induction motor for refrigerator compressors," Energies, vol. 9, no. 3, pp. 1-16, 2016.

[19] G. Y. Zhou and J. X. Shen, "Current harmonics in induction machine with closed-slot rotor," IEEE Transactions on Industry Application, vol. 53, no. 1, pp. 134-142, 2017.

[20] M. Y. Kaikaa, F. Babaa, A. Khezzar, and M. Boucherma, "Analytical analysis of rotor slot harmonics in the line current of squirrel cage induction motors," Journal of Electrical Engineering, vol. 57, no. 1, pp. 12-19, 2006.

[21] M. Dems, K. Komeza, S. Wiak, and S. F. Coya, "Influence of the closing slots on the additional losses in the induction motor," COMPEL-The International Journal for Computation and Mathematics in Electrical and Electronic Engineering, vol. 34, no. 2, pp. 531-549, 2015.

[22] T. Tudorache and L. Melcescu, "FEM optimal design of energy efficient induction machines," Advances in Electrical and Computer Engineering, vol. 9, no. 2, pp. 58-64, 2009.

[23] A. Simion, L. Livadaru, S. Mihai, A. Munteanu, and C.-G. Cantemir, "Induction machine with improved operating performances for electric trucks. A FEM-based analysis," Advances in 
Electrical and Computer Engineering, vol. 10, no. 2, pp. 71-76, 2010.

[24] Z. Li, L. Zhang, X. Yu, and Q. Wang, "Modelling and analysis of two-degree of freedom permanent magnet synchronous generator," EEA - Electrotehnica, Electronica, Automatica, vol. 65, no. 3, pp. 63-69, 2017. 


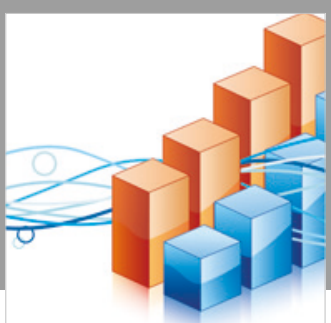

Advances in

Operations Research

\section{-n-m}
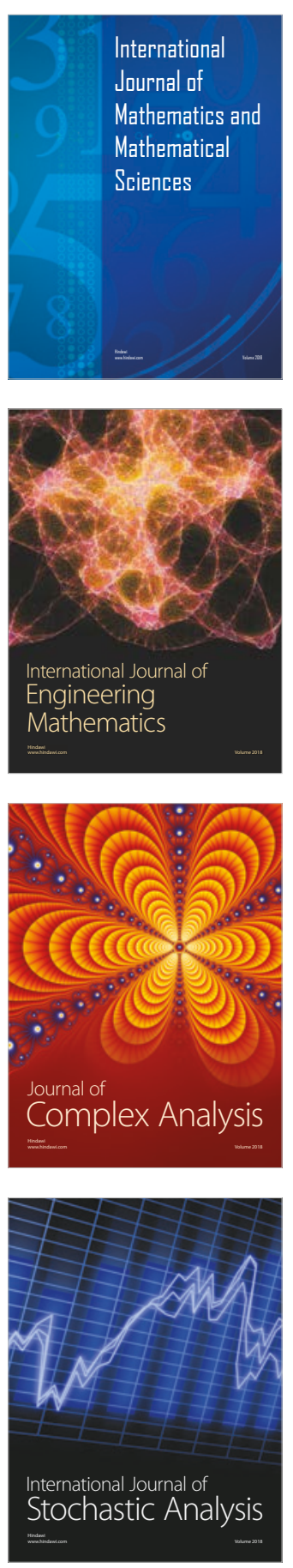
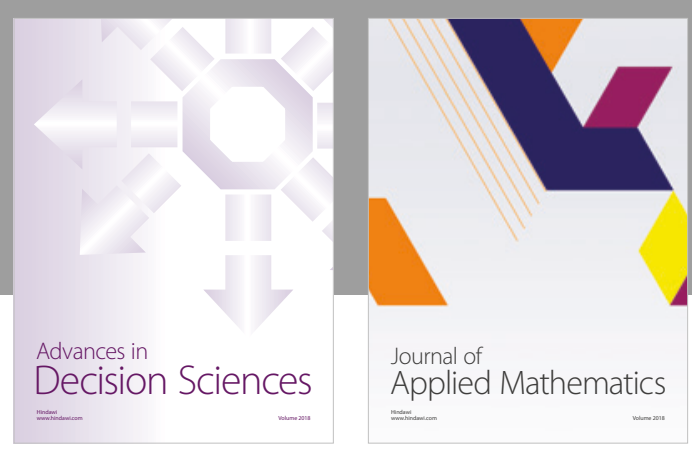

Journal of

Applied Mathematics
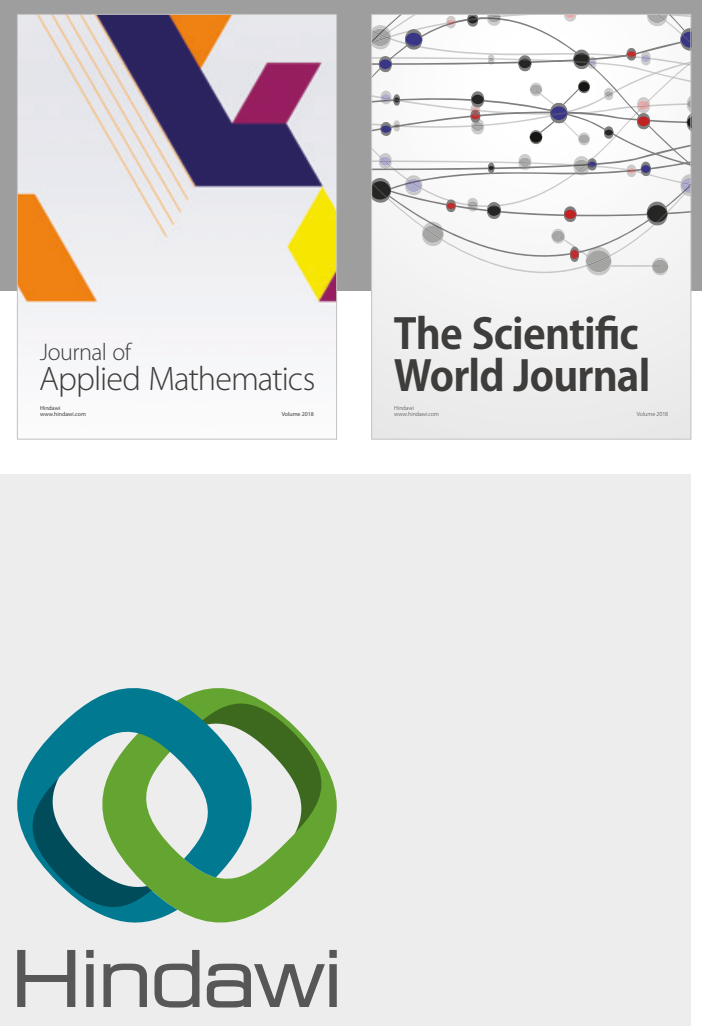

Submit your manuscripts at

www.hindawi.com

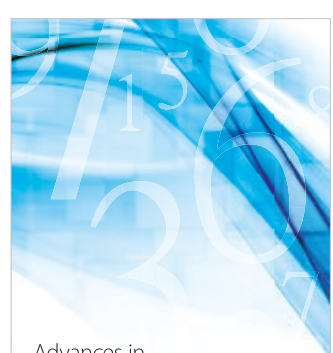

Advances in
Numerical Analysis
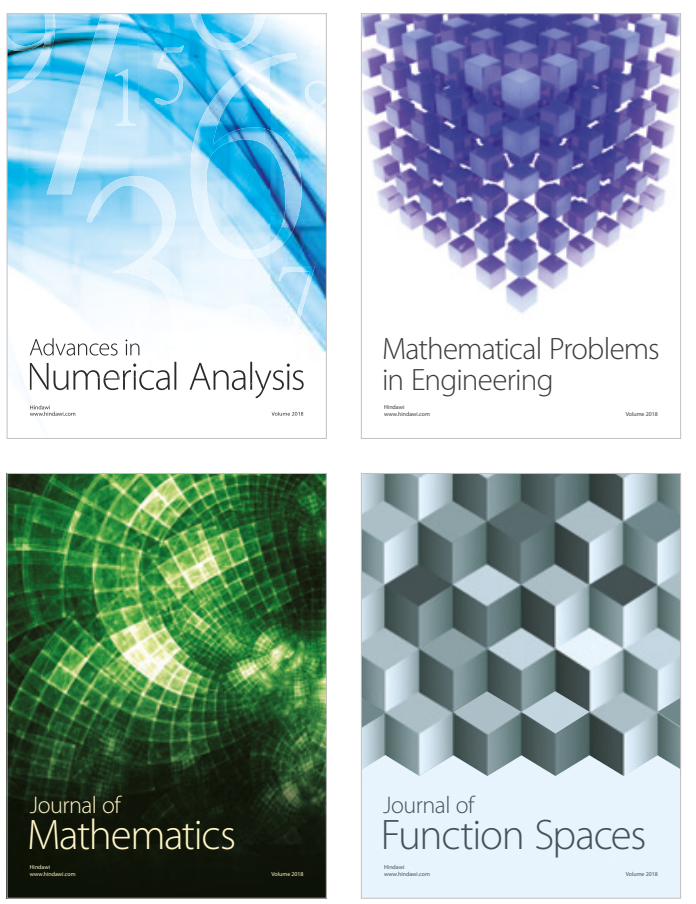

Mathematical Problems in Engineering

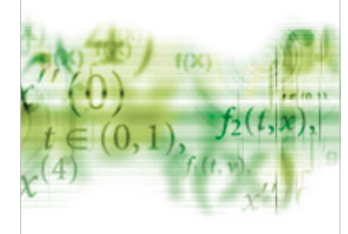

International Journal of

Differential Equations

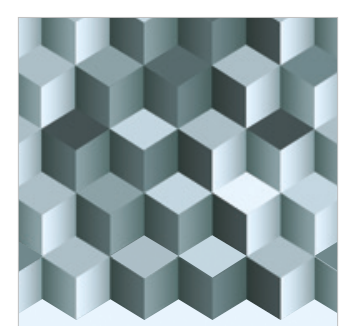

Journal of

Function Spaces

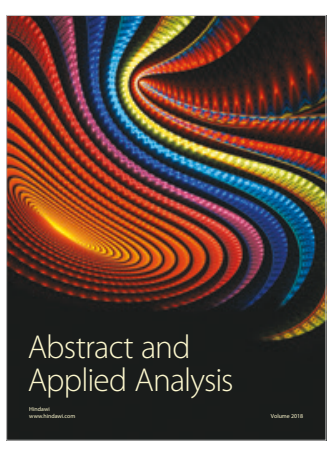

The Scientific

World Journal

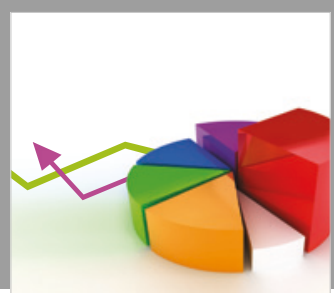

Journal of

Probability and Statistics
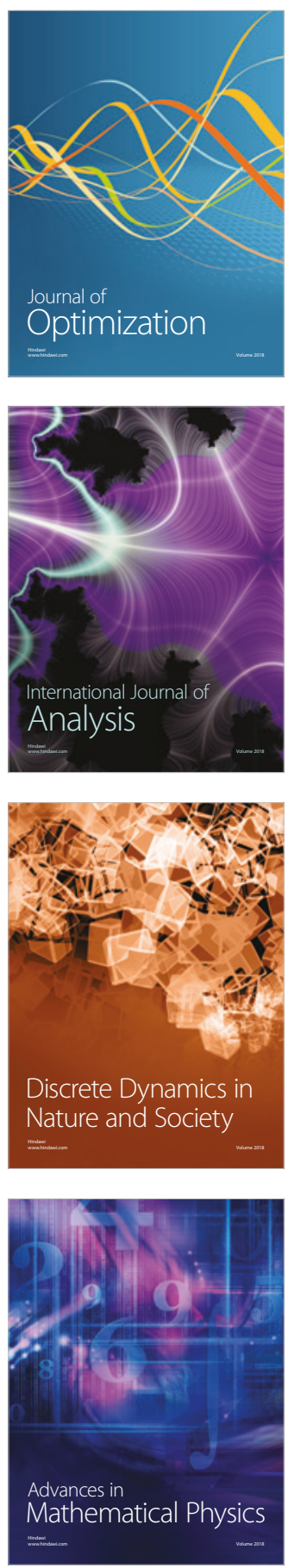